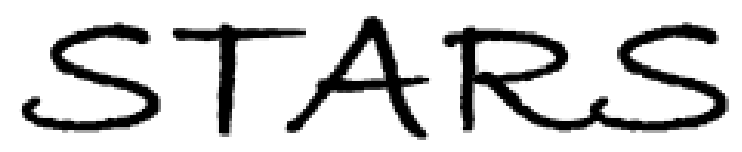

University of Central Florida

STARS

$1-1-1998$

\title{
Synthesis of nanocrystalline diamond thin films from an $\mathrm{Ar}-\mathrm{CH} 4$ microwave plasma
}

D. Zhou

T. G. McCauley

L. C. Qin
A. R. Krauss
D. M. Gruen

Find similar works at: https://stars.library.ucf.edu/facultybib1990 University of Central Florida Libraries http://library.ucf.edu

This Article is brought to you for free and open access by the Faculty Bibliography at STARS. It has been accepted for inclusion in Faculty Bibliography 1990s by an authorized administrator of STARS. For more information, please contactSTARS@ucf.edu.

\section{Recommended Citation}

Zhou, D.; McCauley, T. G.; Qin, L. C.; Krauss, A. R.; and Gruen, D. M., "Synthesis of nanocrystalline diamond thin films from an Ar-CH4 microwave plasma" (1998). Faculty Bibliography 1990s. 2523.

https://stars.library.ucf.edu/facultybib1990/2523

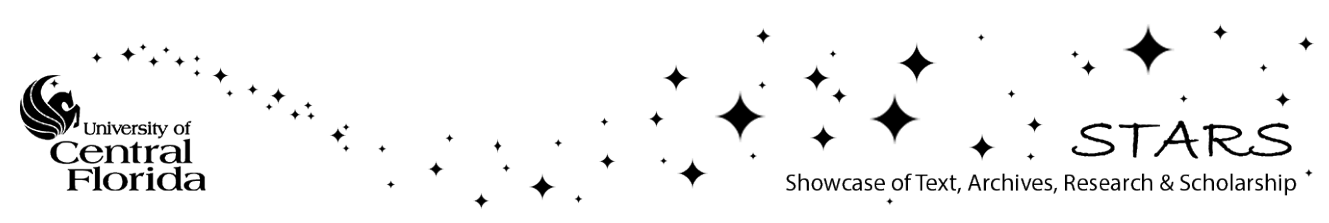




\section{Synthesis of nanocrystalline diamond thin films from an $\mathrm{Ar}-\mathrm{CH}_{4}$ microwave plasma}

Cite as: Journal of Applied Physics 83, 540 (1998); https://doi.org/10.1063/1.366668 Submitted: 16 July 1997 . Accepted: 29 September 1997 . Published Online: 04 June 1998

D. Zhou, T. G. McCauley, L. C. Qin, A. R. Krauss, and D. M. Gruen

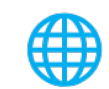

\section{ARTICLES YOU MAY BE INTERESTED IN}

Control of diamond film microstructure by Ar additions to $\mathrm{CH}_{4} / \mathrm{H}_{2}$ microwave plasmas Journal of Applied Physics 84, 1981 (1998); https://doi.org/10.1063/1.368331

Synthesis and characterization of highly-conducting nitrogen-doped ultrananocrystalline diamond films

Applied Physics Letters 79, 1441 (2001); https://doi.org/10.1063/1.1400761

Synthesis and electron field emission of nanocrystalline diamond thin films grown from $\mathrm{N}_{2} / \mathrm{CH}_{4}$ microwave plasmas

Journal of Applied Physics 82, 4546 (1997); https://doi.org/10.1063/1.366190

Lock-in Amplifiers ... and more, from DC to $600 \mathrm{MHz}$

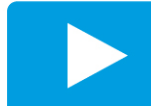

Watch 


\title{
Synthesis of nanocrystalline diamond thin films from an $\mathrm{Ar}-\mathrm{CH}_{4}$ microwave plasma
}

\author{
D. Zhou, ${ }^{\text {a) }}$ T. G. McCauley, L. C. Qin, A. R. Krauss, and D. M. Gruen \\ Materials Science and Chemistry Divisions, Argonne National Laboratory, Argonne, Illinois 60439
}

(Received 16 July 1997; accepted for publication 29 September 1997)

\begin{abstract}
Nanocrystalline diamond thin films have been synthesized in an $\mathrm{Ar}-\mathrm{CH}_{4}$ microwave discharge, without the addition of molecular hydrogen. X-ray diffraction, transmission electron microscopy, and electron energy loss spectroscopy characterizations show that the films consist of a pure crystalline diamond phase with very small grain sizes ranging from 3 to $20 \mathrm{~nm}$. Atomic force microscopy analysis demonstrates that the surfaces of the nanocrystalline diamond films remain smooth independent of the film thicknesses. Furthermore, the reactant gas pressure, which strongly affects the concentration of $\mathrm{C}_{2}$ dimer in the $\mathrm{Ar}-\mathrm{CH}_{4}$ plasma as well as the growth rate of the films, has been found to be a key parameter for the nanocrystalline diamond thin film depositions. (C) 1998 American Institute of Physics. [S0021-8979(98)04501-0]
\end{abstract}

\section{INTRODUCTION}

Atomic hydrogen has long been recognized as playing a crucial role in the growth of polycrystalline diamond films by chemical vapor deposition (CVD), typically using hydrocarbons as the carbon source. ${ }^{1-3}$ It is well known that atomic hydrogen from a hydrogen-rich reactant gas can terminate the carbon dangling bonds with a tetrahedral $s p^{3}$ configuration and etch out nondiamond materials at the growth surface of diamond during the CVD film depositions. ${ }^{4-6}$ Reducing the concentration of atomic hydrogen or increasing the concentration of hydrocarbons in the reactant gas (or plasma) normally causes either nondiamond phase growth or no diamond film deposition. ${ }^{7,8}$ On the other hand, the grain sizes and the surface roughness of the polycrystalline diamond films prepared from a hydrogen-rich plasma depend heavily on the film thickness. Generally, the thicker the film, the bigger the grain size and the rougher the surface of the film.

In order to increase the electron density of the plasma and to modify diamond film morphology, argon has been added independently to plasmas. ${ }^{9}$ Furthermore, argon has also been used in place of hydrogen in a carbon-oxygenargon system, but oxygen was a critical parameter for the phase purity of the deposited diamond films. ${ }^{10}$ Recently, Gruen et al. has reported that nanocrystalline diamond thin films can be grown from an $\mathrm{Ar}-\mathrm{C}_{60}$ microwave plasma without adding molecular hydrogen to the reactant gas. ${ }^{11}$ In Gruen's experiments, fullerenes, such as $\mathrm{C}_{60}$ and $\mathrm{C}_{70}$, have been successfully used as the carbon source for the diamond growth. Through an argon microwave plasma fragmentation of fullerenes (without hydrogen involved), the discharge displays a strong green color (Swan band) due to the $5165 \AA$ emission from the $C_{2}$ radicals, and the $C_{2}$ dimer appears to be the growth precursor of nanocrystalline diamond. ${ }^{12,13}$ Note that the nanocrystalline diamond thin films prepared from an $\mathrm{Ar}-\mathrm{C}_{60}$ microwave plasma with $\mathrm{C}_{2}$ dimers as the

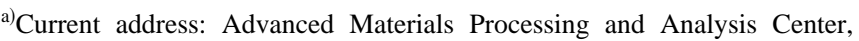
Dept. of Mechanical, Materials, and Aerospace Engineering, University of Central Florida, Orlando, FL 32816.

Electronic mail: dzhou@pegasus.cc.ucf.edu
}

growth precursors have their own unique properties, such as nanocrystalline diamond grains, exceptionally smooth asgrown surfaces, and outstanding electron field emission properties. ${ }^{14,15}$ The growth of nanocrystalline diamond thin films using hydrocarbon as the growth precursors in a plasma enhanced CVD system without hydrogen or oxygen addition, however, appears not to have been studied in detail. ${ }^{16}$

We report here on the growth of nanocrystalline diamond thin films from an $\mathrm{Ar}-\mathrm{CH}_{4}$ microwave plasma without the addition of molecular hydrogen or oxygen. X-ray diffraction (XRD), transmission electron microscopy (TEM), and electron energy loss spectroscopy (EELS) analyses demonstrate that the as-grown films from the $\mathrm{Ar}-\mathrm{CH}_{4}$ plasma consist of phase-pure crystalline diamond grains ranging from 3 to $20 \mathrm{~nm}$ in size independent of the film thickness. Similar to the nanocrystalline diamond films prepared from $\mathrm{Ar}-\mathrm{C}_{60}$ plasmas, the nanocrystalline films synthesized from $\mathrm{Ar}-\mathrm{CH}_{4}$ plasmas also have very smooth surfaces. Based on the study of the optical emission of $\mathrm{C}_{2}$ dimer from the $\mathrm{Ar}-\mathrm{CH}_{4}$ plasmas and the growth rates of the films at different pressures ranging from 55 to 150 Torr, we demonstrate that increasing reactant gas pressure enhances strongly the concentration of $\mathrm{C}_{2}$ in the plasmas, and thus significantly promotes the growth of nanocrystalline diamond thin films.

\section{EXPERIMENTS}

A mixture of $\mathrm{Ar}(99 \mathrm{sccm})$ and $\mathrm{CH}_{4}(1 \mathrm{sccm})$ was employed as the reactant gas for the microwave plasma enhanced CVD thin film preparations. $N$-type single crystal silicon wafers with $\langle 100\rangle$ orientation were used as the substrates, and mechanical polishing with fine diamond powder $(0.1 \mu \mathrm{m})$ was employed to enhance the nucleation density. For all film depositions the substrate temperature and input microwave power were maintained at $800{ }^{\circ} \mathrm{C}$ and $800 \mathrm{~W}$, respectively. The films prepared in this work were either 1 or $5 \mu \mathrm{m}$ thick, as determined by using an in situ laser reflectance interferometer to monitor the modulations of the surface reflectivity during the growth process. ${ }^{17}$ To study the dependence of growth rate of the film on $\mathrm{C}_{2}$ concentration in the plasma, the reactant gas pressure, which strongly affects 


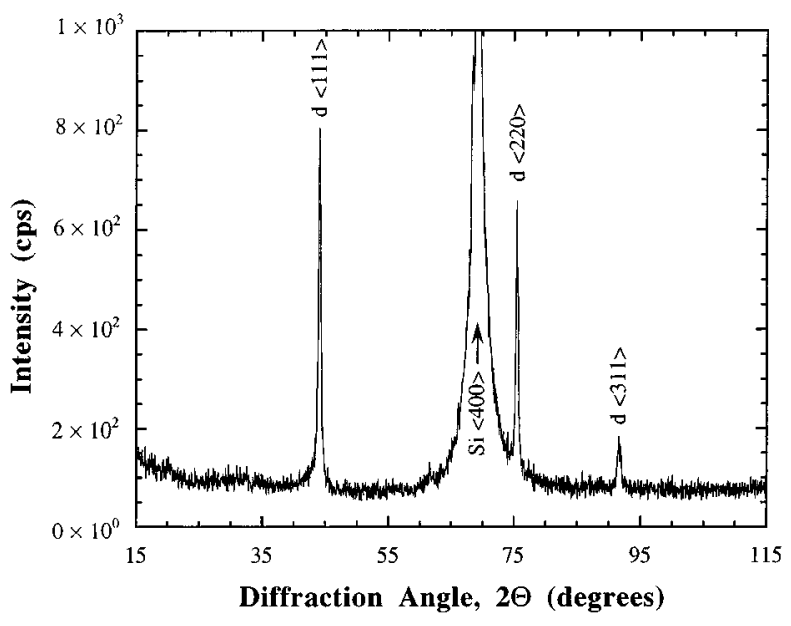

FIG. 1. X-ray diffraction of the as-grown nanocrystalline diamond film prepared from an $\mathrm{Ar}-\mathrm{CH}_{4}$ plasma at 100 Torr. The labels show the diffraction peaks from different planes of the cubic diamond.

production of $\mathrm{C}_{2}$ dimers from the $\mathrm{Ar}-\mathrm{CH}_{4}$ plasmas, was varied from 20 to 150 Torr. A spectrometer equipped with a $1200 \mathrm{GR} / \mathrm{mm}$ grating and water-cooled photomultiplier tube was employed to monitor the $\mathrm{Ar}-\mathrm{CH}_{4}$ plasma, and specially the concentration of $\mathrm{C}_{2}$ dimers. Emission from the plasma was collected with a quartz optical fiber viewing a region 1-2 $\mathrm{cm}$ above the substrate. The monochromater was stepped in $2.3 \AA$ increments with a dwell time of $100 \mathrm{~ms}$ from 3000 to $7000 \AA$. The characterization of the as-grown films was then carried out using XRD, TEM, EELS, and atomic force microscopy (AFM).

\section{RESULTS AND DISCUSSION}

The x-ray diffraction spectrum of the as-grown film is shown in Fig. 1. The diffraction peaks can be indexed on the basis of the cubic diamond structure (see the labels in Fig. 1). The diffraction peaks are significantly broadened due to the very small grain sizes. There is no evidence for graphite or amorphous carbon from the x-ray diffraction. The silicon diffraction peak from $\mathrm{Si}\{400\}$ planes derives from the substrate used for the film deposition. Further characterization of the films has been conducted using TEM. Figure 2(a) shows a plan view TEM image, showing that the film contains very small grains ranging from 3 to $20 \mathrm{~nm}$, but the actual size can be determined more accurately from high resolution TEM images. ${ }^{18}$ The inset image shows a selected area (over $10 \mu \mathrm{m}$ in diameter) electron diffraction of the film, in which the sharp ring pattern illustrates that the diamond grains have a random orientation. EELS was employed as a diagnostic for amorphous or disordered carbon with $s p^{2}$ bonding. It is known that different carbon phases (graphite or amorphous carbon and diamond) have very distinct $K$-shell absorption edge structures. Diamond has a single EELS feature with an onset at $289 \mathrm{eV}$ due to its $\sigma^{*}$ electronic states, while graphite or amorphous carbon has an additional EELS edge starting at $284 \mathrm{eV}$ owing to its lower lying antibonding $\pi^{*}$ states. ${ }^{19}$ Figure 2(b) shows an EELS spectrum of the nanocrystalline diamond film acquired over an area $\sim 10 \mu \mathrm{m}$ in diameter, displaying only an EELS edge at $289 \mathrm{eV}$, characteristic of
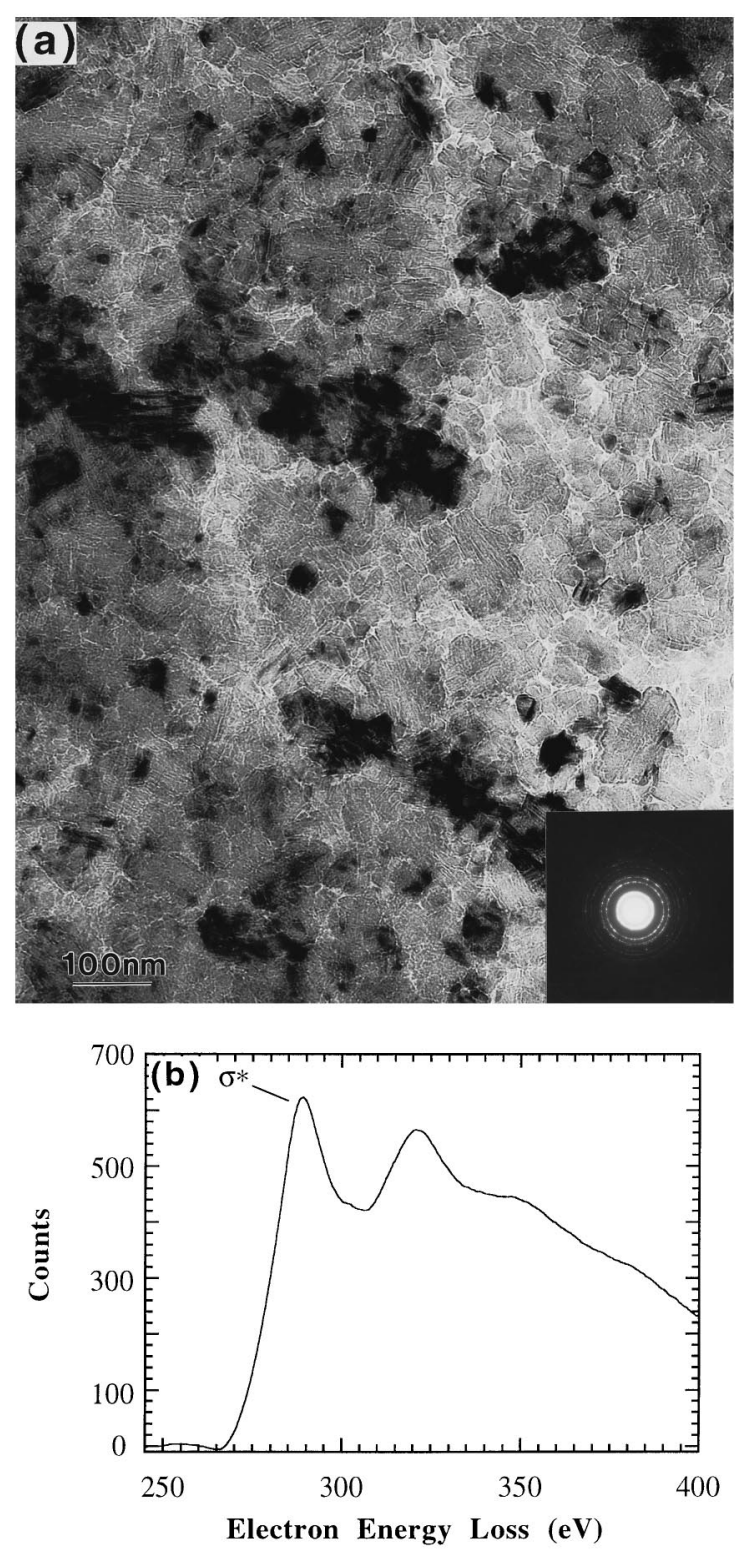

FIG. 2. (a) A plan view TEM image of the diamond film prepared from an $\mathrm{Ar}-\mathrm{CH}_{4}$ plasma at 100 Torr showing that the diamond film consists of nanocrystalline grains ranging from 3 to $20 \mathrm{~nm}$. The inset image shows a sharp ring pattern of a selected area electron diffraction, indicating that the diamond grains have a random orientation; (b) an EELS spectrum of the nanocrystalline diamond film acquired over an area $\sim 10 \mu \mathrm{m}$ in diameter, displaying only an EELS edge at $289 \mathrm{eV}$ corresponding to a $s p^{3}$ electron configuration, characteristic of diamond.

diamond. No energy loss feature at $284 \mathrm{eV}$ has been observed, demonstrating the absence of amorphous or graphite phases in the film. A high resolution TEM image of the nanocrystalline thin film shown in Fig. 3 demonstrates that individual grains are single diamond crystals. The image of lattice fringes has a spacing of $0.205 \mathrm{~nm}$, which is the interplanar distance between diamond $\{111\}$ planes. The lattice image of diamond can only be observed when the diamond $\{111\}$ planes are in proper orientation since the resolution of the TEM used is about $1.8 \AA$.

The surface morphologies of the as-grown nanocrystalline diamond thin films have been studied by AFM. Figure 4 shows three-dimensional AFM images of the films with dif- 


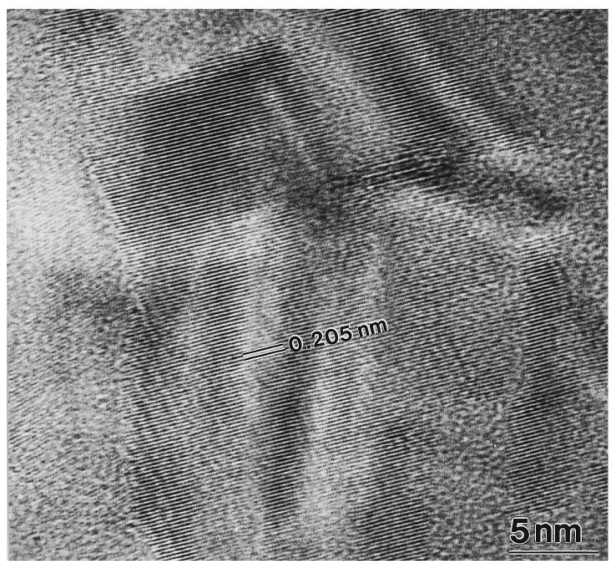

FIG. 3. A high resolution TEM image of the nanocrystalline diamond film produced from an $\mathrm{Ar}-\mathrm{CH}_{4}$ microwave plasma at 100 Torr showing the lattice image of the diamond nanocrystals.

ferent thicknesses of (a) $1 \mu \mathrm{m}$ and (b) $5 \mu \mathrm{m}$, illustrating that the films produced from the $\mathrm{Ar}-\mathrm{CH}_{4}$ plasma have very smooth surfaces. The surface roughness measured over an area of $5 \mu \mathrm{m} \times 5 \mu \mathrm{m}$ for these two films are 36.5 and 38.6 $\mathrm{nm}$, respectively, suggesting that the surface roughness of the nanocrystalline diamond films is largely insensitive to the

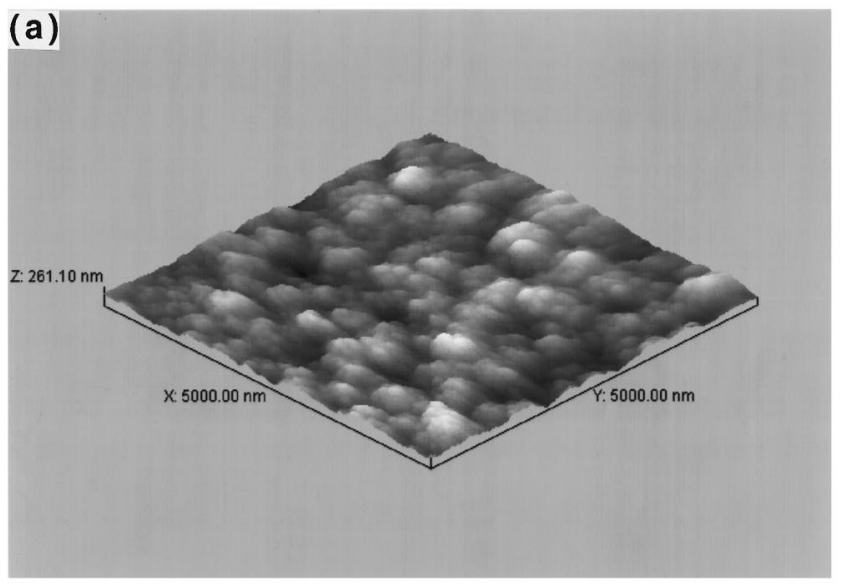

(b)

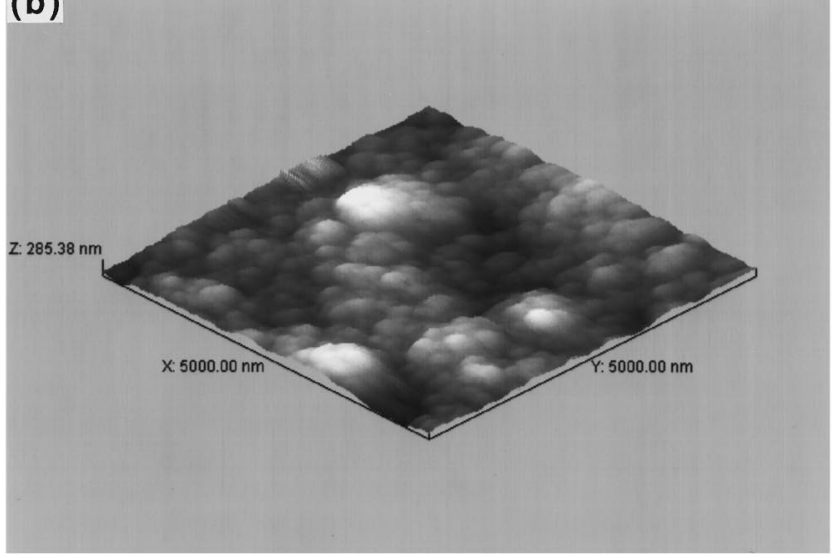

FIG. 4. Three-dimensional AFM images of the films with different thicknesses of (a) $1 \mu \mathrm{m}$ and (b) $5 \mu \mathrm{m}$, illustrating that the nanocrystalline diamond thin films produced from the $\mathrm{Ar}-\mathrm{CH}_{4}$ plasma have very smooth surfaces, which appears to be independent of the film thicknesses.
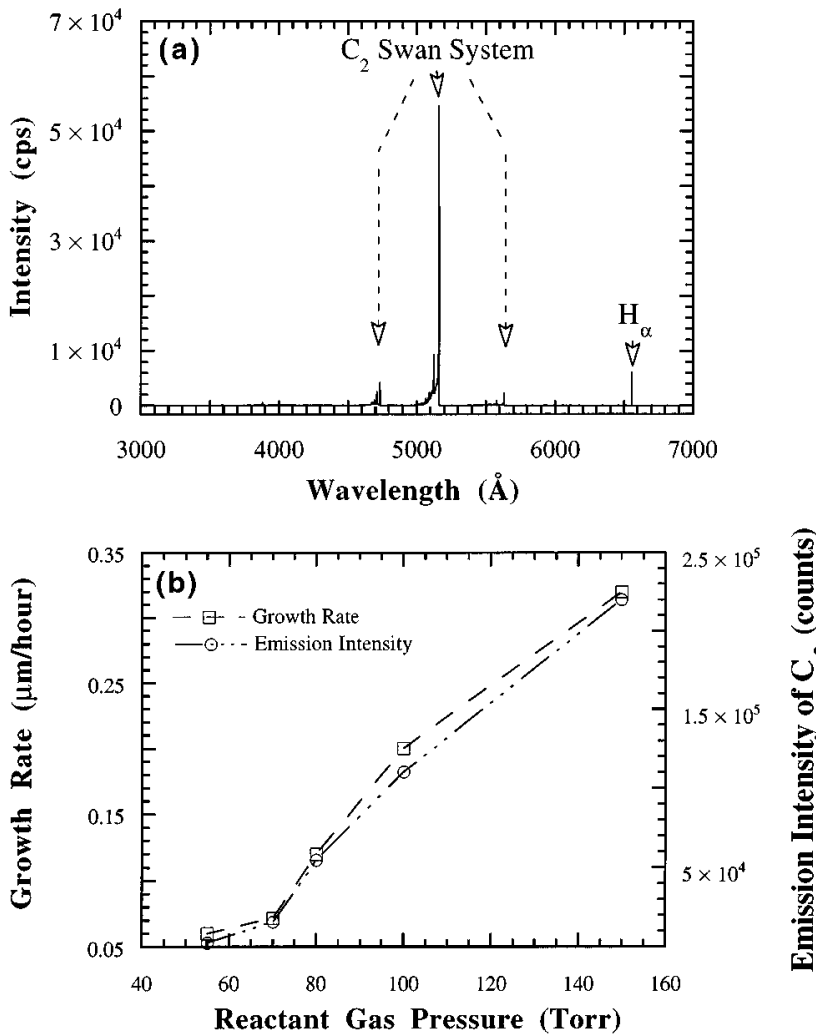

FIG. 5. (a) An optical emission spectrum of the $\mathrm{Ar}-\mathrm{CH}_{4}$ plasma running with 1 vol \% $\mathrm{CH}_{4}$ and 99 vol \% $\mathrm{Ar}$ as the reactant gas at a chamber pressure of 100 Torr; (b) plots of growth rates of nanocrystalline diamond films and emission intensities of $\mathrm{C}_{2}$ from the $\mathrm{Ar}-\mathrm{CH}_{4}$ plasmas vs reactant gas pressures ranging from 55 to 150 Torr.

film thickness, which is in contrast to the conventional CVD polycrystalline diamond films prepared by an atomic hydrogen-rich microwave plasma. Therefore, a new growth precursor such as $\mathrm{C}_{2}$ dimer associated with a novel growth mechanism should be considered for the nanocrystalline diamond thin film deposition from an $\mathrm{Ar}-\mathrm{CH}_{4}$ plasma presented here.

To obtain information from the $\mathrm{Ar}-\mathrm{CH}_{4}$ plasmas, optical emission spectroscopy was employed. Figure 5(a) shows a typical emission spectrum of the $\mathrm{Ar}-\mathrm{CH}_{4}$ plasma running with 1 vol $\% \mathrm{CH}_{4}$ and $99 \mathrm{vol} \% \mathrm{Ar}$ as the reactant gas at the chamber pressure of 100 Torr. In this spectrum, the $C_{2}$ swan system (5165 $\AA$ bands) has been observed through in the wavelength range from 3000 to $7000 \AA$. A weak emission line of $\mathrm{H}_{\alpha}(6562 \AA)$ from atomic hydrogen, which is contributed by the discharge reaction of methane, is also visible in this emission spectrum. Figure 5(b) shows plots of growth rates of nanocrystalline diamond films and emission intensities of $\mathrm{C}_{2}$ from the $\mathrm{Ar}-\mathrm{CH}_{4}$ plasmas versus reactant gas pressures ranging from 55 to 150 Torr, showing that the pressure strongly affects both the $\mathrm{Ar}-\mathrm{CH}_{4}$ discharge chemistry and the nanocrystalline diamond film growth. The growth rates of nanocrystalline thin films deposited from the $\mathrm{Ar}-\mathrm{CH}_{4}$ plasmas are determined by monitoring modulations of the surface reflectivity versus deposition time with a $\mathrm{He}-\mathrm{Ne}$ laser $\left(\begin{array}{lll}6328 & \AA\end{array}\right)$ reflectance interferometer. ${ }^{17}$ One modulation (from peak to peak) presents a film deposition 
$130 \mathrm{~nm}$ thick. The emission intensities of $\mathrm{C}_{2}$, which correlates linearly with the absolute $\mathrm{C}_{2}$ concentration in $\mathrm{Ar}-\mathrm{CH}_{4}$ microwave plasmas, ${ }^{20}$ are directly measured from the $\mathrm{C}_{2}$ swan system (5165 $\mathrm{A}$ bands) in the optical emission spectra. When the reactant gas pressure is below 40 Torr, no $\mathrm{C}_{2}$ emission is detected by our optical emission spectrometer, and no diamond film growth is observed. Similarly, diamond film growth is not observed from $\mathrm{Ar}-\mathrm{CH}_{4}$ plasmas up to 15 Torr. ${ }^{21}$ At 55 Torr, a very low emission intensity of $\mathrm{C}_{2}$ is seen [Fig. 5(b)], and is accompanied by a correspondingly low growth rate of the nanocrystalline diamond thin film is about $0.06 \mu \mathrm{m} / \mathrm{h}$. As the reactant gas pressure increased, both the emission intensity of $\mathrm{C}_{2}$ dimers and the growth rate of the films are increased significantly [see Fig. 5(b)]. Note that the linear relationship between the growth rate and the $\mathrm{C}_{2}$ concentration shown in Fig. 5(b) suggests that the concentration of $\mathrm{C}_{2}$ in the $\mathrm{Ar}-\mathrm{CH}_{4}$ plasma is the factor determining the film growth rate.

Our observations demonstrate that the reactant gas pressure plays an important role in enhancing the emission intensity and therefore the concentration of $\mathrm{C}_{2}$ in $\mathrm{Ar}-\mathrm{CH}_{4}$ plasma. That $\mathrm{C}_{2}$ is the growth species for nanocrystalline diamond is confirmed by the functional relationship between the $\mathrm{C}_{2}$ concentration and the growth rate. Although the $\mathrm{C}_{2}$ dimer can be efficiently produced by $\mathrm{Ar}-\mathrm{CH}_{4}$ discharges, the fragmentation of $\mathrm{C}_{60}$ molecules in an Ar microwave plasma producing $\mathrm{C}_{2}$ appears to be even more efficient as a result of high cross sections for dissociation by metastable argon atoms, by charge exchange with argon ions, by dissociative recombination with electrons, and by thermal processes. ${ }^{22}$ TEM analysis reveals that diamond thin films produced from $\mathrm{Ar}-\mathrm{CH}_{4}$ discharges consist of very small grain sizes ranging from 3 to $20 \mathrm{~nm}$, indicating that renucleation rates must be very high. The very high renucleation rates, which result in nanocrystalline diamond rather than graphite in an $\mathrm{Ar}-\mathrm{CH}_{4}$ plasma, suggest that during the deposition process nucleation of the diamond phase occurs in the absence or near absence of atomic hydrogen.

\section{CONCLUSIONS}

Nanocrystalline diamond thin films have been synthesized by microwave plasma enhanced CVD using a mixture of $\mathrm{Ar}$ and $\mathrm{CH}_{4}$ as the reactant gas without any molecular hydrogen addition. The films consist of a pure nanocrystalline diamond phase with grain sizes ranging from 3 to 20 $\mathrm{nm}$. The films produced from an $\mathrm{Ar}-\mathrm{CH}_{4}$ microwave plasma have very smooth surfaces, which do not depend on the thickness (at least in the range of $1-5 \mu \mathrm{m}$ ) of the film. The reactant gas pressure has been demonstrated to play a very important role in enhancing the concentration of $\mathrm{C}_{2}$ in the plasma, which in turn controls the growth rate. The depen- dence of the growth rates of the nanocrystalline diamond films on the optical emission intensities for the $\mathrm{C}_{2}$ dimer in the plasma supports the mechanism of nanocrystalline diamond growth from $\mathrm{C}_{2}$ dimers proposed by Gruen et al. ${ }^{11,12}$

\section{ACKNOWLEDGMENTS}

The authors wish to thank C. D. Zuiker and T. D. Corrigan for helpful discussions. We also wish to thank A. Goyette for valuable discussions on the optical emission measurement. The research reported here was conducted with support from the United States Department of Energy Office of Basic Energy Science under Contract No. W-31-109ENG-38

${ }^{1}$ B. V. Deryagin, D. V. Fedoseev, N. D. Polyanskaya, and E. V. Statenkova, Sov. Phys. Crystallogr. 21, 239 (1976).

${ }^{2}$ S. Matsumoto, Y. Sato, M. Tsutsumi, and N. Setaka, J. Mater. Sci. 17, 3106 (1981).

${ }^{3}$ P. K. Bachman, D. Leers, and H. Lydtin, Diamond Relat. Mater. 1, 1 (1991).

${ }^{4}$ J. C. Angus, H. A. Will, and W. S. Stanko, J. Appl. Phys. 39, 2915 (1968).

${ }^{5}$ M. Frenklach, J. Appl. Phys. 65, 5124 (1989).

${ }^{6}$ W. L. Hsu, J. Vac. Sci. Technol. 6, 1803 (1988).

${ }^{7}$ Y. Saito, K. Sato, H. Tanaka, K. Fujita, and S. Matsuda, J. Mater. Sci. 23, 842 (1988).

${ }^{8}$ Y. Liou, A. Inspektor, R. Weimer, D. Knight, and R. Messier, J. Mater. Res. 5, 2305 (1990)

${ }^{9}$ H. C. Shih, C. P. Sung, W. L. Fan, and W. L. Hsu, Thin Solid Films 232, 41 (1993)

${ }^{10}$ P. Joeris, C. Benndorf, and S. Bohr, J. Appl. Phys. 71, 4638 (1992).

${ }^{11}$ D. M. Gruen, S. Liu, A. R. Krauss, J. Luo, and X. Pan, Appl. Phys. Lett. 64, 1502 (1994)

${ }^{12}$ D. M. Gruen, X. Pan, A. R. Krauss, A. Liuy, J. Luo, and C. M. Foster, J. Vac. Sci. Technol. A 12, 1491 (1994).

${ }^{13}$ P. C. Redfern, D. A. Horner, A. A. Curtiss, and D. M. Gruen, J. Phys. Chem. 100, 11654 (1996).

${ }^{14}$ C. D. Zuiker, A. R. Krauss, D. M. Gruen, X. Pan, J. C. Li, R. Csencsits, A. Erdemir, C. Bindal, and G. Fenske, Thin Solid Films 270, 154 (1995).

${ }^{15}$ D. Zhou, A. R. Krauss, T. D. Corrigan, T. G. McCauley, R. P. H. Chang, and D. M. Gruen, J. Electrochem. Soc. 144, L224 (1997).

${ }^{16}$ V. I. Konov, A. A. Smolin, V. G. Ralchenko, S. M. Pimenov, E. D. Obraztsova, E. N. Loubnin, S. M. Metev, and G. Sepold, Diamond Relat. Mater. 4, 1073 (1995).

${ }^{17}$ C. D. Zuiker, D. M. Gruen, and A. R. Krauss, J. Appl. Phys. 79, 3541 (1996).

${ }^{18}$ L. C. Qin, D. Zhou, A. R. Krauss, and D. M. Gruen, Nanostructured Mater. (submitted).

${ }^{19}$ J. Fink, T. M. Heinzerling, J. Pfluger, A. Bubenzer, K. Koidl, and G. Crecelius, Solid State Commun. 47, 687 (1983).

${ }^{20}$ A. N. Goyette, J. E. Lawler, A. W. Anderson, T. G. MacCauley, D. M. Gruen, D. Zhou, and A. R. Krauss, J. Mol. Spectrosc. (submitted).

${ }^{21}$ P. Joeris, I. Schmidt, and C. Benndorf, in Applications of Diamond Films and Related Materials: Third International Conference, edited by A. Feldman, Y. Tzeng, W. A. Yarbrough, M. Yoshikawa, and M. Murakawa (National Institute of Standards and Technology, 1995), Spec. Publ. 885, p. 381.

${ }^{22}$ D. M. Gruen, A. R. Krauss, D. Zhou, T. G. McCauley, T. D. Corrigan, R. P. H. Chang, and G. M. Swain, Proceedings of the International Symposium on Chemical Vapor Deposition, Paris, France, 1997 (to be published). 